\title{
Targeting the Nalidixic Acid Binding Site on Human Serum Albumin Through Computational Approach: A Re-Investigation
}

\author{
Adyani Azizah Abd Halim 1,*iD, Farrah Wahidah Ridzwan 2 (D), Saharuddin Bin Mohamad 2,4 (D), Saad \\ Tayyab $^{3,4, *}$ (D)
}

1 Department of Oral and Craniofacial Sciences, Faculty of Dentistry, Universiti Malaya, Kuala Lumpur, Malaysia; adyaniazizah@um.edu.my (A.A.A.H.);

2 Bioinformatics Programme, Institute of Biological Sciences, Faculty of Science, Universiti Malaya, Kuala Lumpur, Malaysia; farrah@um.edu.my (F.W.R.); saharuddin@um.edu.my (S.B.M.);

3 Biochemistry Programme, Institute of Biological Sciences, Faculty of Science, Universiti Malaya, Kuala Lumpur, Malaysia; saadtayyab2004@um.edu.my (S.T.);

4 Centre of Research for Computational Sciences and Informatics for Biology, Bioindustry, Environment, Agriculture and Healthcare, Universiti Malaya, Kuala Lumpur, Malaysia; saharuddin@um.edu.my (S.B.M.); saadtayyab2004@um.edu.my (S.T.);

* Correspondence: adyaniazizah@um.edu.my (A.A.A.H.); saadtayyab2004@um.edu.my (S.T.);

Scopus Author ID 24463315100 (A.A.A.H)

Received: 30.04.2021; Revised: 28.05.20215; Accepted: 3.06.2021; Published: 9.06.2021

\begin{abstract}
Nalidixic acid (NA) is a quinolone drug used to treat urinary tract infections. It inhibits bacterial gyrase-DNA complex formation, an essential step for DNA supercoiling during bacterial replication. Due to the medical application of this drug, it would be interesting to get insight into its binding mechanism with human serum albumin (HSA), the primary carrier protein in blood circulation. Two reports of NA binding to HSA were published using molecular docking approaches. The first report revealed that the preferred binding site of NA was Site II of serum albumins, while the recent finding predicted Site I of bovine serum albumin (BSA) as the preferred site. Given the high sequence homology between these albumins, it is presumed that the binding preference of this drug should be the same in these proteins. To re-investigate this phenomenon, the interaction of NA with HSA was conducted using AutoDockTool 4.0. The molecular docking results revealed that NA binding preference was at Site I, involving Lys 199 in HSA, due to the formation of more significant contacts. Hence, it is concluded that any variable or parameters in the software should be wisely standardized to minimize the controversial results using different programs.
\end{abstract}

Keywords: AutoDock 4.0; human serum albumin; drug-protein binding; molecular docking; nalidixic acid.

(c) 2021 by the authors. This article is an open-access article distributed under the terms and conditions of the Creative Commons Attribution (CC BY) license (https://creativecommons.org/licenses/by/4.0/).

\section{Introduction}

Human serum albumin (HSA) is a primary carrier protein in blood plasma for various exogenous and endogenous ligands. It consists of domains I, II, and III, divided into two subdomains, A and B. Subdomains IIA and IIIA possess the well-known ligand binding sites, viz. Sudlow's Site I and Site II, respectively. These sites have a high affinity to bind various molecules [1-12]. Interaction mechanisms of various ligands, including drugs to HSA using molecular docking programs such as AutoDock and Vina, have been reported [2-12]. These 
tools are used to predict the interaction mechanism by establishing virtual models of drugprotein interactions at the atomic level based on conformations and calculation of binding free energies for respective domains of HSA [2-12]. This information can be used to validate the findings from in-vitro studies while reducing the cost and minimizing the time for the drug discovery process [13].

Nalidixic acid (NA) possesses antibacterial properties for urinary tract treatment. It acts as a gyrase inhibitor by cleaving the bacterial gyrase-DNA complex responsible for bacterial DNA supercoiling during bacterial replication [14]. Its primary and secondary binding sites were proposed to lie in subdomains IIIA and IIA of albumins, respectively, based on results from the Consistent Valence Force Field (CVFF force field) of the software InsightII [15]. Contrary to it, a recent report predicted the preferred binding site of NA as Site 1 of bovine serum albumin (BSA) using AutoDock 4.0 [16]. Since BSA has a high (76\%) sequence homology with HSA, it is assumed that the NA binding site of these albumins should be the same. Herein, we have conducted the molecular docking of NA-HSA interaction using the AutoDock 4.0 program to solve the controversy between these two reports.

\section{Materials and Methods}

\subsection{Molecular docking simulation.}

The chemical structure of NA was constructed using ACD/ChemSketch, followed by the compound energy minimization using MMFF94 force field via Avogadro [17,18]. The three-dimensional (3D) structure of HSA (PDB ID: 1BM0) was obtained from the Protein Data Bank (PDB) with a resolution of $2.5 \AA$ [19]. The preparation of 3D structures of HSA and NA was conducted using AutoDockTools4 [20] by adding non-polar hydrogens and Kollman charges and computing the Gasteiger charges accordingly. The grid coordinates for each of the HSA binding sites were specified according to their respective sites, namely, subdomain IIA and subdomain IIIA [1], to conduct an independent molecular docking simulation. The coordinates $(\mathrm{x}=35.36, \mathrm{y}=32.41$, and $\mathrm{z}=36.46)$ were selected for the binding site on subdomain IIA (Site I), while for subdomain IIIA (Site II), the coordinates were centred at $\mathrm{x}=$ $14.42, \mathrm{y}=23.55$, and $\mathrm{z}=23.31$ with the box dimension $70 \times 70 \times 70$ points and $0.375 \AA$ spacing. The molecular docking of NA to HSA was performed using AutoDock4 [20] utilizing the Lamarckian genetic algorithm search engine with the search runs set to 100 and population size of 150 . Other docking parameters include 0.8 as the operator weights of crossover, 0.02 as the rate of mutation, 150 as the population size and 27,000 as the maximum number of generations. Upon completion, the analysis was conducted to identify the binding energy as well as the interactions involved via AutoDockTools4, LigPlot+ and UCSF Chimera [20-22].

\section{Results and Discussion}

\subsection{Molecular docking simulation analysis.}

Interactions formed between NA and HSA, together with the generated binding energy, dictate the stability of the formed complex. Initial assessment of the docking results was conducted by clustering them based on $2.0 \AA$ of root-mean-squared deviation (RMSD). The cluster analysis (Figure 1) showed that at Site I, there were three multimember conformational clusters formed, whereas there were six clusters formed at Site II. The highest populated cluster, along with its mean binding energy at Sites I and II, were $81\left(-33.72 \mathrm{~kJ} \mathrm{~mol}^{-1}\right)$ and 51 
$\left(-21.25 \mathrm{~kJ} \mathrm{~mol}^{-1}\right)$, respectively. Further inspection showed that the lowest binding energy of the formed complex at Site I was $-34.10 \mathrm{~kJ} \mathrm{~mol}^{-1}$, while the lowest binding energy at Site II was $-22.59 \mathrm{~kJ} \mathrm{~mol}^{-1}$. The formed interactions were evaluated based on the lowest predicted binding energy of NA at HSA binding sites.

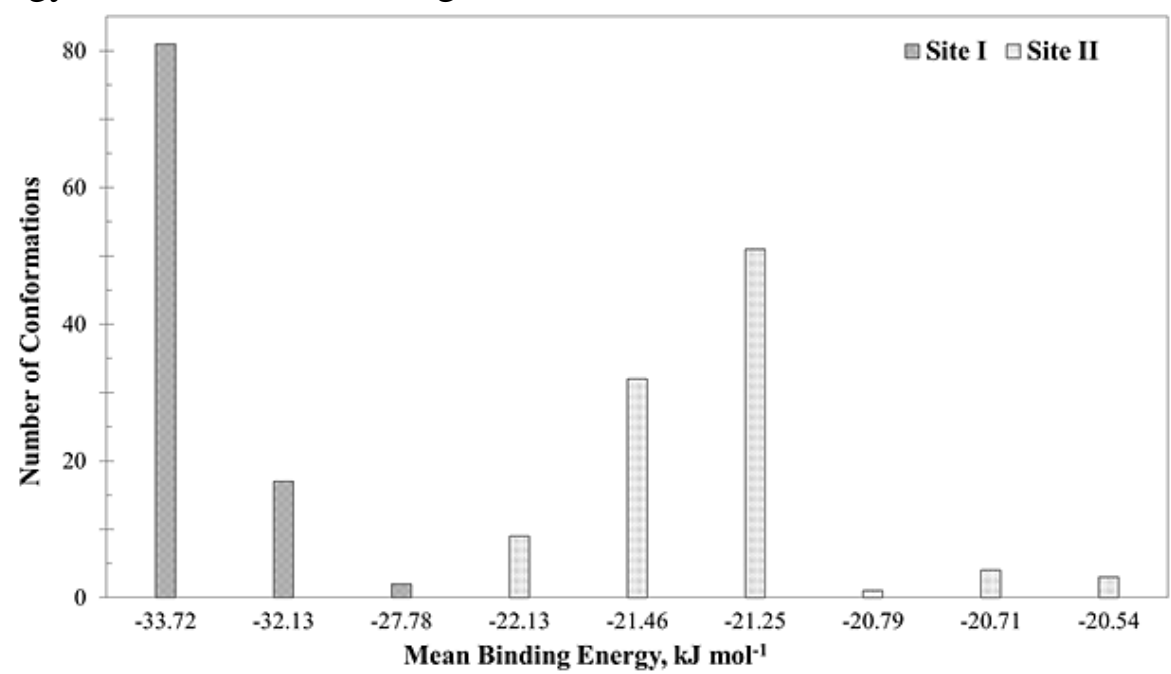

Figure 1. Molecular docking cluster analysis of NA at HSA binding sites (Site I and Site II). A total of 100 runs were conducted on each of the independent docking sites.

As visualized in Figure 2 and detailed in Table 1, three hydrogen bonds were formed between NA and the individual residues of HSA, which were Lys-199, His-242 and Arg-257 at Site I, whereas only one hydrogen bond involving Lys-413 was formed at Site II. The involvement of Lys-199 of HSA in NA-HSA interaction was in line with a recently published report [23]. The higher number of formed hydrogen bonds at Site I would likely contribute to the generated binding energy and hence, the stability of NA on HSA. Moreover, the orientation of NA docked on the HSA Site I was lined by several amino acid residues such as Tyr-150, Phe-223, Leu-238, Leu-260, Ile-264, Ile-290, and Ala-291 (Figure 3), that formed hydrophobic interactions. Meanwhile, only Val-493 contributed to the hydrophobic interactions at Site II, whereas Ser-489 and Glu-492 contributed to polar interactions. These analyses indicated that the preferred binding site for NA on HSA was on Site I, where the hydrogen bonds and hydrophobic interactions mainly contributed to the stable complex formation.

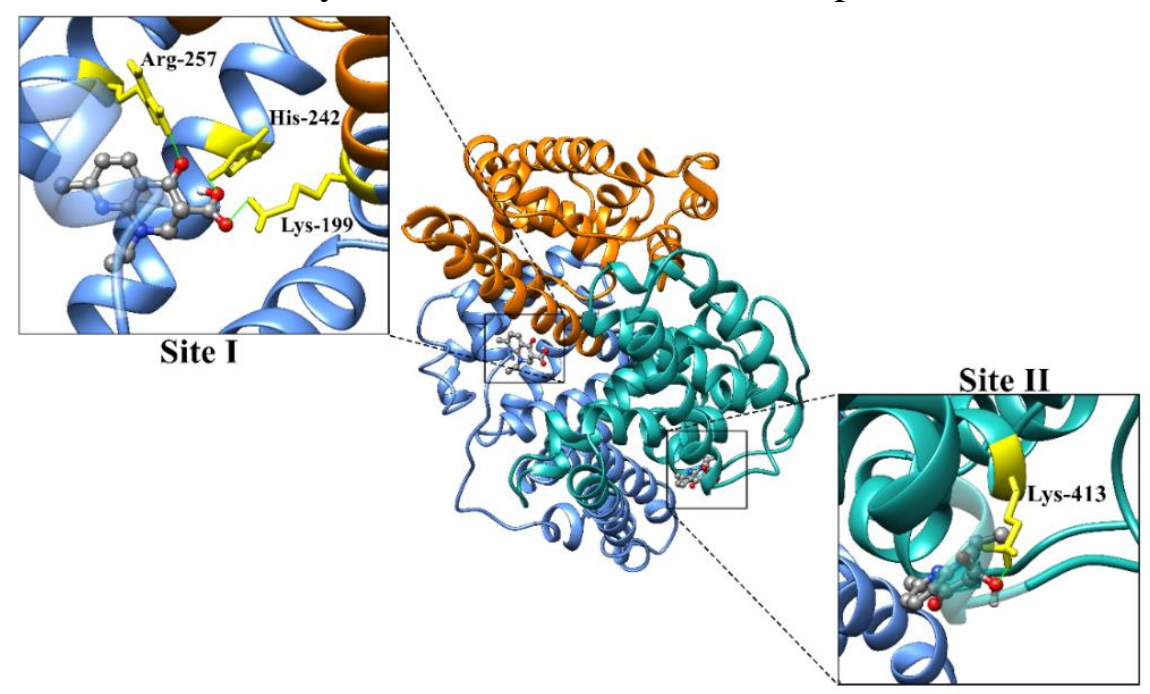

Figure 2. The docked orientation of NA (rendered in the ball and stick) at HSA binding sites based on the predicted lowest binding energy. The domains of HSA are colored accordingly (Domain I: orange, Domain II: blue, and Domain III: green). The zoomed-in image shows the formed hydrogen bonds (green lines) between the HSA residues (rendered in the yellow stick) and NA. 
Table 1. The formed hydrogen bonds interaction between NA and the respective binding sites (Site I and Site II) on HSA, as obtained from the lowest binding energy conformation.

\begin{tabular}{c|c|c|c} 
HSA binding site & HSA residue and atom & NA atom & Distance $(\AA)$ \\
\hline \multirow{2}{*}{$\begin{array}{c}\text { Site I } \\
\text { (subdomain IIA) }\end{array}$} & Lys-199:HZ3 & $\mathrm{O}$ & 1.85 \\
\cline { 2 - 4 } & His-242:HE2 & $\mathrm{O}$ & 2.15 \\
\cline { 2 - 4 } $\begin{array}{c}\text { Site II } \\
\text { (subdomain IIIA) }\end{array}$ & Arg-257:HH22 & $\mathrm{O}$ & 2.13 \\
\hline Lys-413:HZ2 & $\mathrm{O}$ & 1.61
\end{tabular}

$\mathbf{A}$

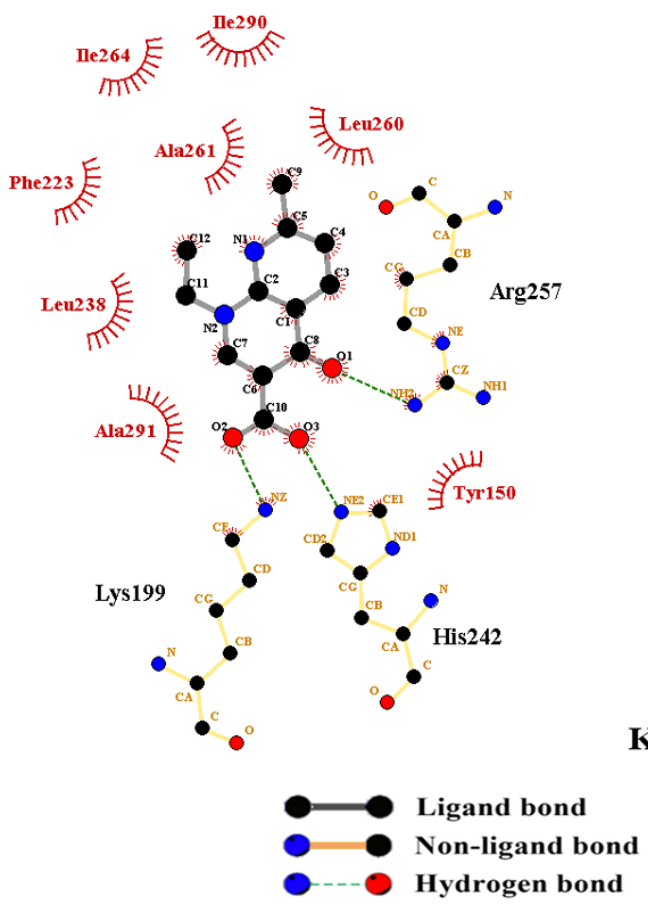

$\mathbf{B}$

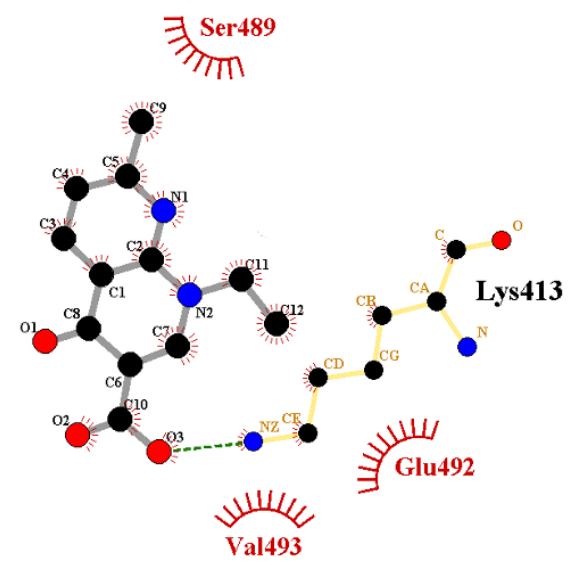

Keys:

Leu259 $\begin{aligned} & \text { Non-ligand residues involved in } \\ & \text { hydrophobic/polar contact(s) }\end{aligned}$
$\begin{aligned} & \text { Corresponding atoms involved in } \\ & \text { hydrophobic/polar contact(s) }\end{aligned}$

Figure 3. The formed hydrophobic and polar interactions between NA and HSA amino acid residues at Site I (A) and Site II (B) generated using LigPlot+.

\section{Conclusions}

Interaction of NA with HSA involved both hydrophobic interactions and hydrogen bonds. Besides, the preferred binding site for NA was identified in subdomain IIA, which was Sudlow's Site I of HSA involving one Lys residue. This result was in line with a recent report suggesting the involvement of lysine residues in NA-HSA interaction [23]. Therefore, these results offer valuable information about the pharmacokinetics of NA in human circulation.

\section{Funding}

This research was supported by a Universiti Malaya Research Grant (RG012/09AFR), sanctioned to S.T.

\section{Acknowledgments}

We thank the Dean, Faculty of Science and the Head, Institute of Biological Sciences, Universiti Malaya, for providing the necessary facilities.

\section{Conflicts of Interest}

The authors declare no conflict of interest. 


\section{References}

1. Tayyab, S.; Feroz, S.R. Serum albumin: Clinical significance of drug binding and development as drug delivery vehicle. Adv Protein Chem Struct Biol. 2021, 123, 193-218, https://doi.org/10.1016/bs.apcsb.2020.08.003.

2. Musa, K.A.; Ridzwan, N.F.W.; Mohamad, S.B.; Tayyab, S. Combination mode of antimalarial drug mefloquine and human serum albumin: Insights from spectroscopic and docking approaches. Biopolymers, 2020, 111, e23337, https://doi.org/10.1002/bip.23337.

3. Tayyab, S.; Min, L.H.; Kabir, M.Z; Kandandapani, S.; Ridzwan, N.F.W.; Mohamad, S.B. Exploring the interaction mechanism of a dicarboxamide fungicide, iprodione with bovine serum albumin. Chem Pap. 2020, 74, 1633-1646, https://doi.org/10.1007/s11696-019-01015-1.

4. Kabir, M.Z.; Roslan, A.A.; Ridzwan, N.F.W.; Mohamad, S.B.; Tayyab, S. Biomolecular interaction of a platelet aggregation inhibitor, 3,4-methylenedioxy-B-nitrostyrene with human serum albumin: Multi-spectral and computational characterization. J Biomol Struct Dyn. 2020, 38, 2693-2703, https://doi.org/10.1080/07391102.2019.1640133.

5. Kandandapani, S.; Ridzwan, N.F.W.; Mohamad, S.B.; Tayyab, S. Exploring the interaction between tyrphostin 9 and human serum albumin using biophysical and computational methods. J Biomol Struct Dyn. 2020, 38, 4134-4142, https://doi.org/10.1080/07391102.2019.1673210.

6. Musa, K.A.; Ning, T.; Mohamad, S.B.; Tayyab, S. Intermolecular recognition between pyrimethamine, an antimalarial drug and human serum albumin: Spectroscopic and docking study. J Mol Liq. 2020, 311, 113270, https://doi.org/10.1016/j.molliq.2020.113270.

7. Francis, J.A.; Shalauddin, M.; Ridzwan, N.F.W.; Mohamad, S.B.; Basirun, W.J.; Tayyab, S. Interaction mechanism of an antimalarial drug, sulfadoxine with human serum albumin. Spectrosc Lett. 2020, 53, 391405, https://doi.org/10.1080/00387010.2020.1764588.

8. Kabir, M.Z.; Benbekhti, Z.; Ridzwan, N.F.W.; Merrouche, R.; Bouras, N.; Mohamad, S.B.; Tayyab, S. Biophysical and in silico investigations of the molecular association between a potent RNA polymerase inhibitor, thiolutin and human serum albumin. $J$ Mol Liq. 2020, 303, 112648, https://doi.org/10.1016/j.molliq.2020.112648.

9. Roslan, A.A.; Mohamad, S.B.; Tayyab, S. Docking evaluation of the interaction between green tea active ingredient, L-theanine and human serum albumin. Natl Acad Sci Lett. 2021, 44, 17-19, https://doi.org/10.1007/s40009-020-00949-5.

10. Musa, K.A.; Ridzwan, N.F.W.; Mohamad, S.B.; Tayyab, S. Exploring the combination characteristics of lumefantrine, an antimalarial drug and human serum albumin through spectroscopic and molecular docking studies. J Biomol Struct Dyn. 2021, 39, 691-702, https://doi.org/10.1080/07391102.2020.1713215.

11. Salim, M.M.; El Sharkasy, M.E.; Belal, F.; Walash, M. Multi-spectroscopic and molecular docking studies for binding interaction between fluvoxamine and human serum albumin. Spectrochim Acta A Mol Biomol Spectrosc. 2021, 252, 119495, https://doi.org/10.1016/j.saa.2021.119495.

12. Shiekhzadeh, A.; Sohrabi, N.; Eslami-Moghadam, M.; Divsalar, A.; Soltani, N.; Oftadeh, M.; Fateminasab, F. Spectroscopic and docking molecular study of new anticancer Pt complex binding with human serum albumin. Nucleos Nucleot Nucl Acids 2021, 40, 369-392, https://doi.org/10.1080/15257770.2021.1880010.

13. Lin, X.; Li, X.; Lin, X. A Review on Applications of Computational Methods in Drug Screening and Design. Molecules 2020, 25, 1375, https://doi.org/10.3390/molecules25061375.

14. Gross, C.H.; Parsons, J.D.; Grossman, T.H.; Charifson, P.S.; Bellon, S.; Jernee, J.; Dwyer, M.; Chambers, S.P.; Markland, W.; Botfield, M.; Raybuck, S.A. Active-site residues of Escherichia coli DNA gyrase required in coupling ATP hydrolysis to DNA supercoiling and amino acid substitutions leading to novobiocin resistance. Antimicrob Agents Chemother. 2003, 47, 1037-1046, https://doi.org/10.1128/aac.47.3.10371046.2003.

15. Monti S.; Manet I.; Manoli F.; Capobianco M.L.; Marconi G. Gaining an insight into the photoreactivity of a drug in a protein environment: A case study on nalidixic acid and serum albumin. J Phys Chem B. 2008, 112, 5742-5754, https://doi.org/10.1021/jp711261n.

16. Siddiqui, S.; Mujeeb, A.; Ameen, F.; Ishqi, H.M.; Rehman, S.U.; Tabish, M. Investigating the mechanism of binding of nalidixic acid with deoxyribonucleic acid and serum albumin: A biophysical and molecular docking approaches. J Biomol Struct Dyn. 2021, 39, 570-585, https://doi.org/10.1080/07391102.2020.1711808.

17. Halgren, T.A. Merck molecular force field. I. Basis, form, scope, parameterization, and performance of MMFF94. J Comput Chem. 1996, 17, 490-519, https://doi.org/10.1002/(SICI)1096987X(199604)17:5/6<490::AID-JCC1>3.0.CO;2-P. 
18. Hanwell, M.D.; Curtis, D.E.; Lonie, D.C.; Vandermeersch, T.; Zurek, E.; Hutchison, G. R. Avogadro: An advanced semantic chemical editor, visualization, and analysis platform. J Cheminform. 2012, 4, 17, https://doi.org/10.1186/1758-2946-4-17.

19. Sugio, S.; Kashima, A.; Mochizuki, S. Crystal structure of human serum albumin at $2.5 \AA$ resolution. Protein Eng. 1999, 12, 439-446, https://doi.org/10.1093/protein/12.6.439.

20. Morris, G. M.; Huey, R.; Lindstrom, W.; Sanner, M. F.; Belew, R. K.; Goodsell, D. S.; Olson, A. J. Autodock4 and AutoDockTools4: Automated docking with selective receptor flexibility. J Comput Chem. 2009, 30, 2785-2791, https://doi.org/10.1002/jcc.21256.

21. Laskowski, R.A.; Swindells, M.B. LigPlot+: Multiple ligand-protein interaction diagrams for drug discovery. J Chem. Inf. Model. 2011, 51, 2778-2786, https://doi.org/10.1021/ci200227u.

22. Pettersen, E.F.; Goddard, T.D.; Huang, C.C.; Couch, G.S.; Greenblatt, D.M.; Meng, E.C.; Ferrin, T.E. UCSF Chimera - A visualization system for exploratory research and analysis. J Comput Chem. 2004, 25, 16051612, https://doi.org/10.1002/jcc.20084.

23. Tan, C.Y.; Lim, C.S.; Liew, S.M.; Abd Halim, A.A.; Tayyab, S. Lysine modification of human serum albumin and its effect on protein conformation and nalidixic acid binding. J. Indian Chem. Soc. 2021, 98, 100031, https://doi.org/10.1016/j.jics.2021.100031. 